\title{
Quantification of anti-fertility compound-Diosgenin concentration in the fenugreek seeds aqueous extract (FSA)
}

\author{
Ahmed Kaid $N A^{a}$, Norbaiyah $M B^{a}$, Imad $M A^{a}$, Norazian $M H^{b}$ \\ ${ }^{a}$ Department Basic Medical Science (BMS), Kulliyyah of Medicine (KOM), International Islamic University \\ Malaysia (IIUM), Kuantan Malaysia. \\ ${ }^{b}$ Kulliyyah of Pharmacy, IIUM, Kuantan Malaysia.
}

\section{ABSTRACT}

Introduction: This study aims to build a standardization method for preparation of effective powder from FSA and to quantify diosgenin in FSA. Methodology: One kg of FS were used in this study. Setting: BMS, KOM and KOP, IIUM Kuantan campus. FS were washed with distilled water to exclude any foreign matter, and were then air dried. FS-powder were put in distilled water in a ratio of $1 \mathrm{~g}$ of powder in $20 \mathrm{ml}$ of distilled water and were shaken at room temperature for 24 hours. Ten $\mathrm{mg}$ of hydrolyzed extract sample was diluted in $10 \mathrm{ml}$ volumetric flask with methanol for 15 minutes. Chromatographic estimation was performed using an equilibrated reverse phase Eclipse XDB-C18 column (particle size $5 \mu \mathrm{g}, 4.6 \mathrm{~mm} \times 150 \mathrm{~mm}$ ). Results: One gram of FSA extract was hydrolyzed to produce sapogenins and $46.6 \%$ was recovered. A calibration curve that was constructed based on five dilutions of diosgenin standard at concentrations of $2,5,10,20,30$ and $50 \mathrm{ppm}$ produced a linear graft $(r=0.999)$. The concentration of diosgenin in FSA extract as calculated using the regression analysis was found to be $29.66 \mu \mathrm{g} / \mathrm{ml}, 13.81 \% \mathrm{w} / \mathrm{w}$ on dried weight basis. Conclusion: Preparation and standardization of effective powder from FSA are the corner stone of many scientific researches in IIUM and Malaysia. Diosgenin is available in the FSA in adequate concentration. The adequate amount of diosgenin in the FSA will guide us to do further study in the way of preparation of a natural product that can be used in the field of reversible anti-fertility therapy.

KEYWORDS: Diosgenin, FSA, anti-fertility.

\section{INTRODUCTION}

Diosgenin is a naturally occurring steroidal saponin present in a variety of plants including fenugreek (Trigonella foenum graecum) and roots of wild yam (Dioscorea villosa). ${ }^{1}$ In the old and recent traditional medicine, the plant-origin saponins have been used for many disorders ${ }^{2-4}$ including cancers. ${ }^{5}$ The natural steroid saponin is a diosgenin. Diosgenin is a major bioactive constituent seeds of fenugreek. ${ }^{6}$ Many synthetic steroids are consisted of diosgenin. It is involved in the treatment of obesity, diabetes, inflammations and various kinds of cancer. $^{7}$

Corresponding author:

Ahmed Kaid N. Allaw,

Department Basic Medical Science (BMS),

Kulliyyah of Medicine (KOM),

International Islamic University Malaysia

(IIUM),

Kuantan Malaysia.

HP: +60177772162

Office: $+609-5704507$

Email: ivf2007@gmail.com;
Reference to the ethnobotanical use of fenugreek seeds appears in the Egyptian Ebers papyrus (c. 1500 BC) as a medicine to induce childbirth. Fenugreek seeds were referred as a "soothing herb" by the Greek physician Hippocrates (5th century BC) and Dioscorides (1st century $A D$ ), and they were use in the treatment of gynaecological inflammation. ${ }^{8}$ Fenugreek seeds and leaves are reported to have anti-diabetic, anti-fertility, ${ }^{9}$ anticancer, antimicrobial, anti-parasitic and hypocholesterolaemic, effects. ${ }^{10}$

The medical use of fenugreek seeds as anti-fertility agent against reproduction has not been studied, especially in the effect of diosgenin within the fenugreek seeds in family planning. Family planning is an essential component of primary health care which includes birth control, spacing birth and doctor-patients consultation in deciding the best method of contraception. In recent times with more women being involved in the work force and with expanding cost of raising children, a planned parenthood seems to provide benefit to the physical, 
emotional and mental health of mothers, children, families and communities. ${ }^{11}$ With birth control, parents would be able to provide each child with adequate attention, sufficient shelter, food and clothing as well as good education and medical care. Family planning is also important to prevent high risk pregnancies. The four classifications of high risk pregnancies are; too young (maternal age less than 18 years), too old (maternal age more than 35 years), too many (after four births) and too close (less than 2 years apart). ${ }^{12}$

In poor countries with high rates of population growth such as in the African countries, promotion of family planning has the potential to reduce poverty and prevent $32 \%$ of all maternal death and nearly $10 \%$ of childhood death. Unfortunately, this program has failed to achieve mileage due to minimal political support, insufficient funding and lack of awareness among populations. In addition, contemporary contraception methods are relatively expensive to these low income communities, poorly accessible and surrounded by various myths and cultural barriers that limit contraception practice among this targeted population. ${ }^{13}$

The present study aims to:

1. Build a standardization method in the Department of Basic Medical Science (BMS), Kulliyyah of Medicine (KOM), International Islamic University Malaysia (IIUM) as well as the preparation of an effective powder from fenugreek seeds that could be used in future for experimental and medical purposes.

2. Quantify the active antifertility-compound Diosgenin concentration in the fenugreek seeds.

\section{METHODOLOGY}

\section{Preparation of FSA Extract}

A kilogram of fenugreek seeds were purchased from the local market in Yemen/Rada'a. The seeds were identified by Dr Norazian Mohd Hassan of Kulliyyah of Pharmacy (KOP), IIUM. The voucher specimen was deposited at the Herbarium, KOP, with voucher number PIIUM 0195. FSA extract was prepared at the Herbal Research Laboratory of KOP, IIUM. FSA extract was prepared as described by Khalki et al.(2010) with modification. ${ }^{14}$ Fenugreek seeds were washed with distilled water to exclude any foreign material, and were then air dried. The seeds were grounded into fine powder by using an electrical blender (Pensonic Blender, PB-3203L, Malaysia).

Fenugreek seed powder was put in distilled water in a ratio of $1 \mathrm{~g}$ of powder in $20 \mathrm{ml}$ of distilled water. The sample was agitated with continuous shaking on a shaker (Memmert Shaker, Model 8W, Germany) at room temperature for 24 hours to ensure the fenugreek seeds powder were thoroughly soaked and dissolved in water solvent. Then, the aqueous extract was transferred into $50 \mathrm{ml}$ falcon tubes (SARSTEDT AG \& Co., Germany) and centrifuged at $9000 \mathrm{rpm}$ for 5 minutes by using a centrifuge machine (Hettich Universal 32R, Germany). Later, the supernatant (yield of the extract) was collected. The yield of the extract was then freezed dried for 7 days, using a freeze dryer machine (Martin Christ, Model Alpha 1-4, Germany) to convert the extract into powdered form. The extract was stored in a freezer (Sanyo, MDF-U5312, USA) at $-20^{\circ} \mathrm{C}$ until further use. The percentage yield of fenugreek aqueous extract produced was calculated according to the following formula;

\section{Weight of the freeze dried extract $(\mathrm{g}) \times 100$ Weight of the plant material $(\mathrm{g})$}

2. Hydrolysis of steroidal saponin in FSA extract Hydrolysis of steroidal saponins into diosgenin was performed as described by Krider et al. (1957). ${ }^{[14]}$ One gram of FSA extract was dissolved in $50 \mathrm{ml}$ of distilled water. Then, the aqueous extract was acidified to $\mathrm{pH} 1.4$ with hydrochloric acid. The mixture was then refluxed at $70{ }^{\circ} \mathrm{C}$ for four hours. Later, the precipitate of the aqueous extract was centrifuged (Hettich Universal 32R, Germany) at $9000 \mathrm{rpm}$ for five minutes.

The residual was collected and this partially hydrolyzed saponin was further hydrolyzed by boiling in the water bath for another four hours in 2 . normal hydrochloric acid. The diosgenin was then recovered by centrifuging, and the residual was freeze dried using a freeze dryer machine (Martin Christ, Model Alpha 1-4, Germany). The percentage recovery of hydrolyzed FSA extract was calculated. ${ }^{15}$

3. HPLC quantification of diosgenin in FSA extract Quantification of diosgenin was performed using a HPLC instrument, (Agilent Technologies 1200 Series, United State of America) applying the standard method described by Warke et al.(2011). ${ }^{16}$

\section{a. Preparation of Diosgenin Standard Solution}

Diosgenin standard (Brand Sigma, >93\%, 5g) was purchased from Permula Chemicals Sdn. Bhd. (Malaysia). $2 \mathrm{mg}$ of diosgenin standard was weighted and dissolved in $1 \mathrm{ml}$ methanol for 15 minutes. The solution later was diluted up to $2 \mathrm{ml}$ with methanol $(1 \mathrm{mg} / \mathrm{ml}) .1 \mathrm{ml}$ solution from stock solution was 
pipetted out and diluted up to $10 \mathrm{ml}$ with methanol (100 ug/ml or $100 \mathrm{ppm}$ ).

\section{b. Chromatographic Conditions}

Chromatographic estimation was performed using an equilibrated reverse phase Eclipse XDB-C18 column (particle size $5 \mu \mathrm{g}, 4.6 \mathrm{~mm} \times 150 \mathrm{~mm}$ ). The experimental conditions were an isocratic binary system of acetonitrile/water $(90: 10 \mathrm{v} / \mathrm{v})$, a flow rate of $1 \mathrm{ml} / \mathrm{min}$ with UV and a temperature of $33^{\circ} \mathrm{C}$. Detection was performed at $203 \mathrm{~nm}$.

\section{Calibration Curve of Diosgenin}

Diosgenin calibration curve was established with five dilutions at concentrations of 2, 5, 10, 20, 30 and 50 ppm. Each concentration was measured in triplicate. The corresponding peak areas were plotted against the concentration of diosgenin injected. Peak identification was achieved by comparison of both the retention time (Rt) and UV absorption spectrum for standard.

\section{d. Preparation of FSA Hydrolyzed Extract Solution} $10 \mathrm{mg}$ of hydrolyzed extract sample was diluted in $10 \mathrm{ml}$ volumetric flask with methanol for 15 minutes. Then $1 \mathrm{ml}$ of the solution was diluted up to $10 \mathrm{ml}$.
Each solution was filtered through membrane filter $0.45 \mu \mathrm{m}$ into HPLC vials. Ten $\mu \mathrm{l}$ of sample was injected into the injector in triplicate.

e. Quantitative Analysis for Diosgenin Concentration in FSA Extract

The diosgenin concentrations in the FSA extract samples was calculated through a regression analysis from the peak area and the known concentrations of standard diosgenin samples and are the average of three consecutive readings for each sample

\section{RESULTS}

\section{Percentage yield of FSA extract}

Fenugreek seeds powder $180 \mathrm{~g}$ was processed to produce the extract. The percentage of yield extract is $15.89 \pm 0.487$ with character pale yellow, spongy like powder.

One gram of FSA extract was hydrolyzed to produce sapogenins and $46.6 \%$ was recovered. Table 1 displays the percentage recovery of hydrolyzed FSA extract.

Table 1: The percentage recovery of hydrolyzed FSA extract.

\begin{tabular}{lll}
\hline Weight of hydrolyzed & Percentage & Characteristic \\
FSA extract (g) & recovery (\%) &
\end{tabular}

\begin{tabular}{lll}
\hline 0.466 & 46.6 & Brown colour, fine powder
\end{tabular}

Quantification of diosgenin concentration in the FSA extract.

A satisfactory result with sharp well defined and resolved peak with minimum tailing was achieved using a mobile phase consisting acetonitrile: water in the ratio of $90: 10 \mathrm{v} / \mathrm{v}$. Chromatogram from the
HPLC analysis showed the peak area for diosgenin standard was recognized at retention time (Rt) 11.089 minutes (Figure 1), whereas the peak area for sample solution was recognized at Rt 11.057 minutes (Figure 2), both at $203 \mathrm{~nm}$ UV wavelength.

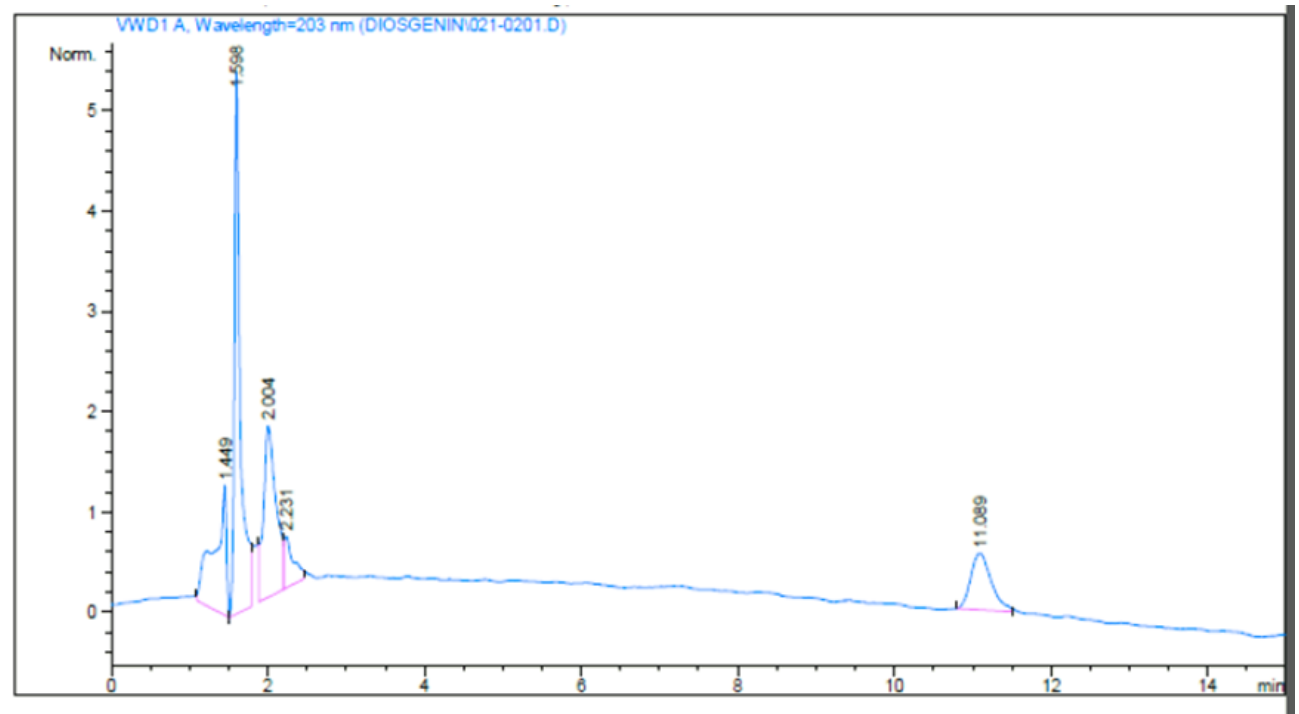

Figure 1: Chromatogram of diosgenin standard. Peak (Rt $11.089 \mathrm{~min})$, Mobile Phase :-Acetonitrile: Water (90:10, V/V), $203 \mathrm{~nm}$ 


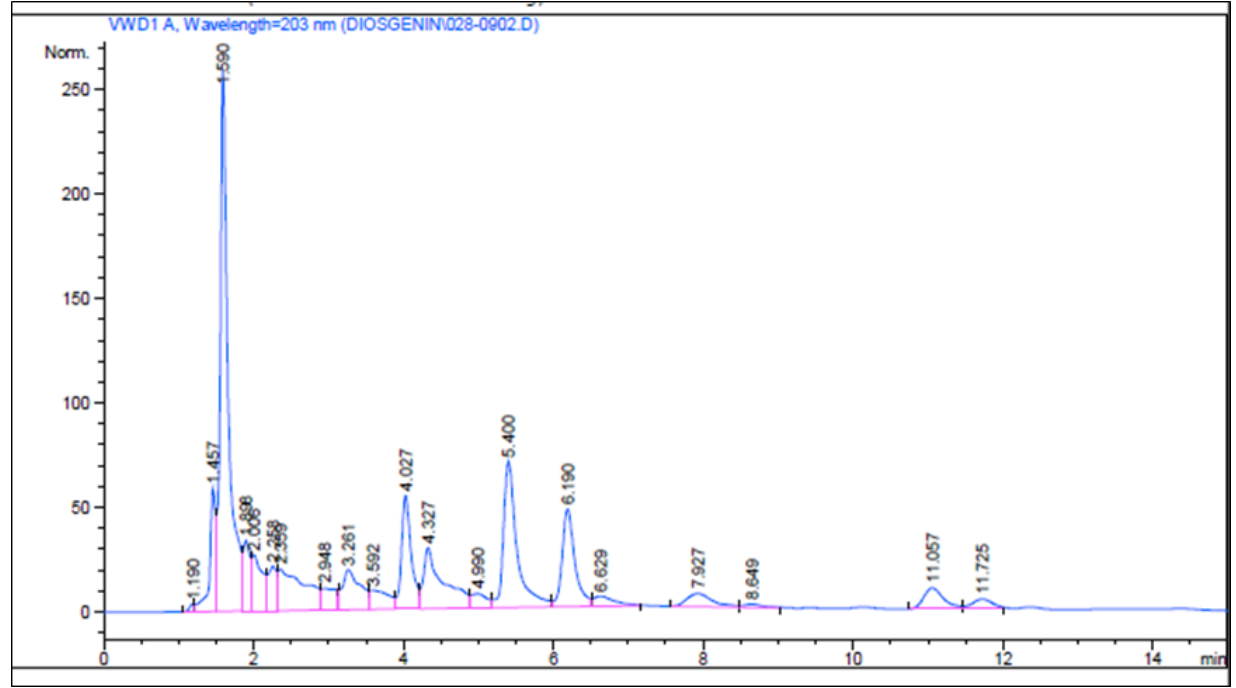

Figure 2: Chromatogram of hydrolyzed FSA extract. Peak (Rt $11.057 \mathrm{~min}$ ), Mobile Phase:-Acetonitrile: Water $(90: 10, \mathrm{~V} / \mathrm{V}), 203 \mathrm{~nm}$

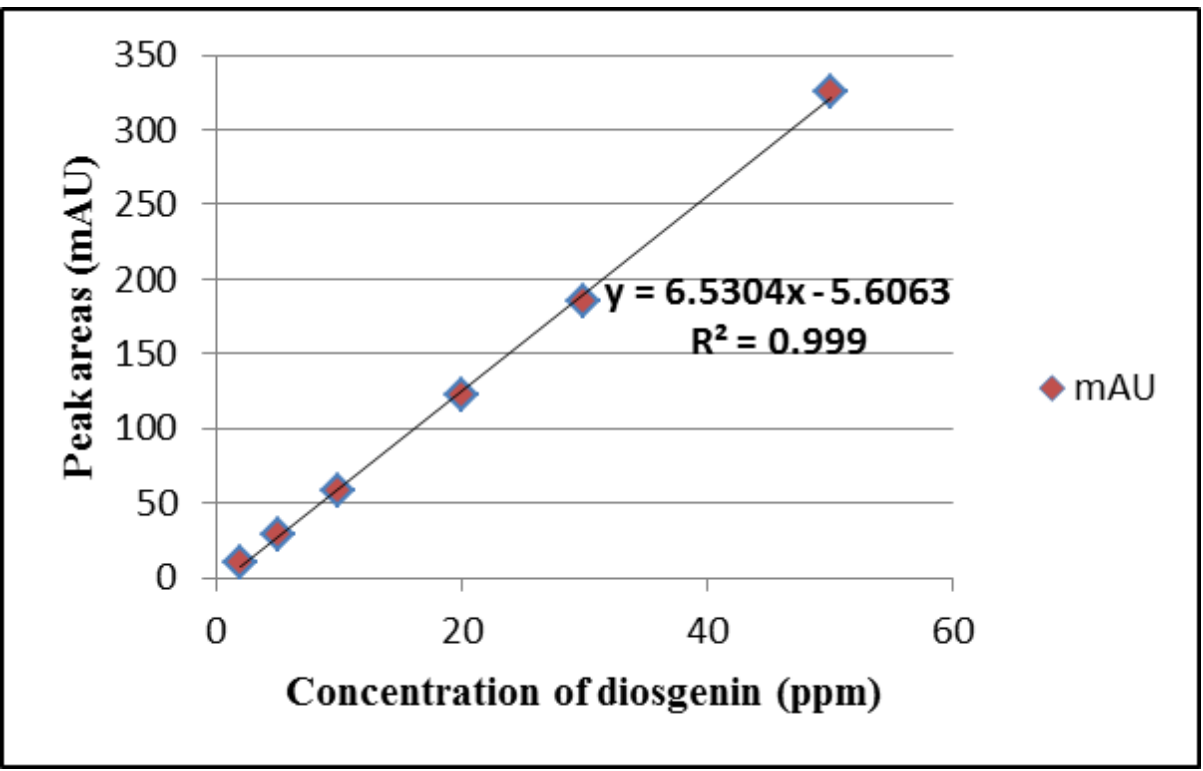

Figure 3: Calibration curve for diosgenin standard solution

HPLC conditions used in this analysis had been confirmed by system suitability test. The parameters of HPLC conditions were within the ranges of normal conditions; (theoretical plate number more than 2000, resolution more than 2 , USP tailing factor less than 2 and capacity factor more than 2). Therefore, the HPLC method applied in the study was reliable.
A calibration curve that was constructed based on five dilutions of diosgenin standard at concentrations of $2,5,10,20,30$ and 50 ppm produced a linear graft $(r=0.999)$ as shown in figure 3. The concentration of diosgenin in FSA extract as calculated using the regression analysis (Table 2) was found to be $29.66 \mu \mathrm{g} / \mathrm{ml}, 13.81 \% \mathrm{w} / \mathrm{w}$ on dried weight basis (Table 3 ) Table 4).

Table 2: Regression analysis of calibration curve for diosgenin standard solution.

\begin{tabular}{ll}
\hline Parameter & Diosgenin \\
\hline Linearity range $(\mathrm{ppm} / \mu \mathrm{g} / \mathrm{ml})$ & $2-50$ \\
Slope & 6.530 \\
Intercept & -5.606 \\
Correlation co efficient $\mathrm{r}^{2}$ & 0.999 \\
\hline
\end{tabular}


Table 3: Result of system suitability parameter obtained for the method

\begin{tabular}{ll}
\hline Parameter & Diosgenin \\
\hline Retention time $(\min )$ & 11.143 \\
Theoretical plate number $(\mathrm{N})$ & $9181(>2000)$ \\
Resolution & $5.159(>2)$ \\
USP tailing factor & $1.342(<2)$ \\
Capacity factor & $10.175(>2)$ \\
\hline
\end{tabular}

Table 4: Diosgenin concentration in FSA extract

\begin{tabular}{llllll}
\hline Sample & $\begin{array}{l}\text { Peak areas } \\
(\mathrm{mAU})\end{array}$ & $\begin{array}{l}\text { Concentration } \\
(\mathrm{ppm} / \mu \mathrm{g} / \mathrm{ml})\end{array}$ & $\begin{array}{l}\text { Mean } \\
(\mathrm{ppm} / \mu \mathrm{g} / \mathrm{ml}) \\
\pm \mathrm{SD}\end{array}$ & $\begin{array}{l}\text { Amount } \\
(\% \mathrm{w} / \mathrm{w}))\end{array}$ & $\begin{array}{l}\text { Mean } \\
(\% \mathrm{w} / \mathrm{w}) \pm \mathrm{SD}\end{array}$ \\
\hline 1 & 182.68 & 28.83 & & 13.44 & \\
2 & 188.94 & 29.79 & $29.65 \pm 0.751$ & 13.88 & $13.81 \pm 0.349$ \\
3 & 192.34 & 30.31 & & 14.13 & \\
\hline
\end{tabular}

\section{DISCUSSION}

The fenugreek seeds used in the present study were purposely purchased at a local market in Furghan/ Rada'a, Yemen i.e. form a well known original source. These fenugreek seeds were locally and naturally grown and harvested in this village. Unlike fenugreek seeds in the Malaysian local market, most of them were imported from other countries and the original source of the seeds was unknown.

The yield percentage of $15.9 \%$ shows that the suitability of water as polar solvent to produce optimal extraction of the constituents. This is consistent with the folkloric use of fenugreek in traditional practice; fenugreek seeds are usually parched or boiled in warm water to be consumed. ${ }^{17}$ Aqueous extract was used in the present study due to the capacity of water solvent to extract the saponin, specifically diosgenin; the bioactive constituent that is believed to be attributed to the anti-fertility effects of fenugreek. ${ }^{18}$

The present study has shown $1 \mathrm{~g}$ of FSA extract contains approximately $29.65 \mu \mathrm{g} / \mathrm{ml}$ diosgenin $(13.81 \% \mathrm{w} / \mathrm{w})$. Since 1941, diosgenin extracted from Mexican yam has been used as raw material for sex steroids such as norethindrone. ${ }^{19}$

Laila et al. in 2014 were found to contain diosgenin in the range of $0.113-0.135 \%(\mathrm{w} / \mathrm{w})$ and quercetin in the range of $0.009-0.012 \%(\mathrm{w} / \mathrm{w}) .{ }^{20}$ They reported that high performance thin-layer chromatographic method is an attractive simple, rapid, and selective method for the simultaneous quantitative determination of flavonoid quercetin and steroid diosgenin in fenugreek extract. They suggested also that this method could be widely applied for direct routine analysis and quality assurance of related extracts and drugs. Through this reported method, bioactive constituents of other plants with such attributes could be identified and used for selection of suitable genotypes that can be further developed into cultivars specific for the natural health product processing industry. ${ }^{20}$

A sensitive and reproducible thin-layer chromatographic method has been developed for quantitation of diosgenin, a spiroketal sapogenin had been published by Trivedi et al. 2007. ${ }^{21}$ The method was successfully applied to various plant samples of fenugreek with a recovery of $98.111 .4 \%$. Dried plant samples and a market formulation were analyzed and found to contain diosgenin in the range of $0.5290 .658 \%(\mathrm{w} / \mathrm{w})$ in fenugreek seed powders, $0.087 \%(\mathrm{w} / \mathrm{w})$ in fenugreek leaf powder, 0.015 and $1.27 \%(\mathrm{w} / \mathrm{w})$ in fenugreek stem powder and extract, respectively, and $0.586 \%(\mathrm{w} / \mathrm{w})$ in a formulation containing fenugreek seed powder. ${ }^{21}$

Given the nature of fenugreek as an annual plant, easily available and widely cultivated around the world, it could be a potential alternative in the supply of diosgenin. 


\section{CONCLUSIONS}

The present study concludes that

1. Preparation and standardization of effective powder from fenugreek seeds is the corner stone of many scientific researches in IIUM and Malaysia.

2. Diosgenin is available in the FSA in adequate concentration.

3. The adequate amount of diosgenin in the FSA will guide us to do further study in the way of preparation a natural product that may be used for reversible anti-fertility therapy.

\section{ACKNOWLEDGMENT}

The authors are thankful to staff of Kulliyyah of Medicine and Kulliyyah of Pharmacy for their help and academic assistance.

\section{REFERENCES}

1. Raju J, Mehta R. Cancer chemopreventive and therapeutic effects of diosgenin, a food saponin. Nutr Cancer 2009; 6:27-35.

2. McAnuff MA, Harding W, Omoruyi FO et al. Hypoglycemic effects of steroidal sapogenins isolated from Jamaican bitter yam, Dioscorea polygonoides. Food Chem Toxicol 2005; 43:1667-1672.

3. Son IS, Kim J, Sohn HY, Son KH, Kim JS. Antioxidative and hypolipidemic effects of diosgenin, a steroidal saponin of yam (Dioscorea spp.), on high-cholesterol fed rats. Biosci Biotechnol Biochem 2007; 71:3063-3071.

4. Chen PS, S.Y., Huang HC, and Cheng HW. Diosgenin, a Steroidal Saponin, Inhibits Migration and Invasion of Human Prostate Cancer PC-3 Cells by Reducing Matrix Metalloproteinases Expression. PLoS ONE 2011; 6:e20164.

5. Fernández-Herrera MA, López-Muñoz $\mathrm{H}$, Hernández-Vázquez JM et al. Synthesis of 26hydroxy-22-oxocholestanic frameworks from diosgenin and hecogenin and their in vitro antiproliferative and apoptotic activity on human cervical cancer CaSki cells. Bioorg Med Chem 2010; 18:2474-2484.

6. Taylor WG, Elder JL, Chang PR, \& Richards KW. Microdetermination of diosgenin from fenugreek (Trigonella foenum-graecum) seeds. J Agric Food Chem 2000; 48:5206-5210.

7. Smith M. Therapeutic applications of fenugreek. Altern Med Rev 2003; 8:20-27.

8. Chevallier A. The encyclopedia of herbal medicine. $2^{\text {nd }}$ edition Dorling Kindersley, Ltd. London., 2000.

9. Allow AK, Rashad AAT, Saeed MS \& Bracamonte MA. Life-Birth Rate Following Metformin MonoTherapy in mono-Cycle Anavulatory Yemeni Infertile Women with Polycystic Ovarian Syndrome-PCOS. Benha Med J 2009; 26:325-
341.

10. Al-Habori M \& Raman A. Pharmacological Properties in Fenugreek. The genus Trigonella (1st edition) by G.A. Petropoulos (ed.), Taylor and Francis, London and New York, 2002; 163 182:163-182.

11. Belfield T. FPA Contraceptive Handbook: The Essential Reference Guide for Family Planning and Other Health Professionals. 1999; Family Planning Association.

12. Senanayake P\& Potts $M$. Atlas of contraception. The encyclopedia of visual medicine series 1995, Pearl River, New York. Parthenon Pub. Group.

13. Cleland J, Bernstein S, Ezeh A et al. Family planning: the unfinished agenda. The Lancet 2006; 368:1810-1827.

14. Khalki L, M'Hamed SB, Bennis M, Chait A, \& Sokar Z. Evaluation of the developmental toxicity of the aqueous extract from Trigonella foenum-graecum (L.) in mice. J Ethnopharmacol 2010. 131: 321-325.

15. Krider MM \& Wall ME. Partial acidic hydrolysis of steroidal saponins. 1957, United States Patent Office No 2,780,620.

16. Warke VB, Deshmukh TA \& Patil VR. Development and validation of RP-HPLC method for estimation of diosgenin in pharmaceutical dosage form. Asian Journal of Pharmaceutical and Clinical Research 2011; 4:126-128.

17. Chauhan G, Sharma M, Kharkwal H \& Varma A. Pharmacognostic, preliminary phytochemical studies and anticancerous potential of Trigonella foenum-graecum. Pharma Sci Monitor 2011; 2:72-81.

18. Francis G, Kerem Z, Makkar HP \& Becker K. The biological action of saponins in animal systems: a review. Br J Nutr 2002; 88:587-605.

19. Speroff $L$ and Darney Philip D. A clinical guide for contraception. Lippincott Williams \& Wilkins., 2010.

20. Laila OI, Abdin MZ, Ahmad S, et al. Development and Validation of HPTLC Method for Simultaneous Estimation of Diosgenin and Quercetin in Fenugreek Seeds (Trigonella foenum-graceum). ISRN Chromatography 2014.

21. Trivedi PD, Pundarikakshudu K, Ratnam S \& Shah KS. A Validated Quantitative Thin-Layer Chromatographic Method for Estimation of Diosgenin in Various Plant Samples, Extract, and Market Formulation. J AOAC Int 2007; 90:358-363. 